\title{
A Practical Teaching Mode for Colleges Supported by Artificial Intelligence
}

\author{
https://doi.org/10.3991/ijet.v15i17.16737
}

Cuibi Yang $(\bowtie)$, Shuliang Huan, Yong Yang

Chongqing Three Gorges University, Chongqing, China

lisaycb1978@163.com

\begin{abstract}
In the era of big data, artificial intelligence (AI) has been widely applied in higher education, providing technical supports to practical teaching in colleges and universities. This paper mainly creates an AI-based practical teaching mode for cultural industry management major of Chongqing Three Gorges University. Firstly, an intelligent management cloud platform was established for practical teaching, drawing the merits from Massive Open Online Course (MOOC) and Self-Paced Open Course (SPOC). Meanwhile, the AI technique was adopted to realize personalized learning and provide intelligent push services. In this way, the online MOOC+SPOC platform seamlessly integrates the teaching content into specific teaching scenarios, and the offline cloud platform manages the teaching process in an intelligent manner. Under the proposed teaching mode, the teaching content could match the job competence standards and the actual abilities of college students. The research results provide a new mode of practical teaching that covers all dimensions and promotes personalized and collaborative learning.
\end{abstract}

Keywords-Artificial intelligence (AI), practical teaching, colleges, massive open online course (MOOC), self-paced open course (SPOC).

\section{$1 \quad$ Introduction}

In recent years, with the rapid development of Internet of Things (IoT), big data and cloud computing, the innovative integration of $\mathrm{AI}$ and college education has become a major trend. Although it has brought great challenges to education in various countries around the world, it also provided more opportunities, ideas and methods for the reform of teaching modes and teaching methods in colleges and universities in various countries. In April 2018, the Ministry of Education of China issued the Action Plan for Artificial Intelligence Innovation in Higher Education, which clearly pointed out that "we must accelerate the innovative application of AI in the field of education, use intelligent technology to support the innovation of talent training modes, the reform of teaching methods, and the improvement of education administration capabilities, and construct an intelligent, networked, personalized, and life-long education system; it is an important means of promoting balanced development of education, promoting education equity, and improving education quality; and it's an indispensa- 
ble driving force and support for the modernization of education [1]." It can be seen that the development of AI technology has opened up a brand-new development path for college education, in particular, it provides a technical guarantee for the research on the application of AI in the practical teaching modes of colleges and universities.

\section{Overview of AI}

AI (Artificial Intelligence) has an early origin and was first proposed by American scholar John McCarthy in 1956 [2], AI technology refers to artificial methods that use computers to imitate human thinking and actions such as planning, thinking, learning, reasoning, understanding, identifying, proving, and problem solving, etc., and solving complex problems that only human experts can solve, such as programming, forecasting, consulting, and diagnosing, etc. [3-6]. AI is an important branch developed on the basis of computer technology, it is an extension based on the intelligence of human, and it's called "the top technology of the 21 st century".

In recent years, due to the breakthroughs of technologies such as deep learning, AI has become one of the most important technologies in the technical revolution at the beginning of this century [7]. It mainly has 8 functions: the first is search and solution, these two are the main functions of AI, and they are the processes of repeatedly performing certain operations, inferences, or calculations for the purpose of achieving a certain goal; the second is knowledge and logical reasoning, and knowledge is the foundation of intelligent technology; the third is memory and association, unrelated things can be connected together via the intelligent technology; the fourth is learning and discovery, the performance of the technology can be improved through the constant learning of the data; the fifth is perception and communication, AI can communicate with people through voice recognition; the sixth is invention and creation; the seventh is system and construction; and the eighth is application and engineering. AI technology can be combined with different fields and it has a wide application range.

Since AlphaGO had defeated the human Go champion in 2016, the basic AI technologies such as Internet+, cloud computing, machine learning, and neural networks have been improved continuously, and AI has entered the "fourth stage" of rapid development [8]. At this stage, the development of AI technology focuses more on the technology transformation and practical application, causing fundamental changes in social institutions, economic structure, production mode and lifestyle, etc. Technology companies, scientific research institutions and universities around the world have successively built up AI laboratories to promote deeper-level AI research and the application of $\mathrm{AI}$ in the fields of education, transportation, finance, and economy, etc. Education is the center in the AI technology revolution of this time [9], and AI technology revolution has a high degree of application attribute in education, enabling the college education reform to transform from theories to practice, and from school experiments to social industries; it can improve education quality and efficiency, change the educational ecology in colleges and universities, affect the outcome of higher 
education, promote higher education equity, truly alter the development path of colleges and universities in China, and thereby change people's lives and behaviors.

\section{Construction of Practical Teaching Mode in Colleges and Universities}

\subsection{Practical teaching in colleges and universities}

The practical teaching in colleges and universities refers to all practical teaching activities that college teachers let students engage in besides the systematic lecturing of theoretical knowledge for the purpose of consolidating and deepening the learnt knowledge, and exercising and improving the comprehensive qualities of students. The goal is to enable students to participate in the curriculum practice activities in person and apply the learnt theoretical knowledge to the specific production, living, and practice, so that they could have the ability to solve practical problems and strengthen their will power, and we could cultivate them to have the correct values and good moral characters. Practical teaching in colleges and universities is an important part of higher education and a key content of college students' learning. The level of practical teaching directly affects the proficiency and depth of the students' mastery of the learnt knowledge, thus affecting their professional competitiveness.

Taking the cultural industry management major in Chongqing Three Gorges College as an example, this major was established in 2011, although not long, it is a very practical discipline that not only requires students to master the relevant theoretical knowledge of the cultural industry, but also the industry itself and the relevant technologies in the industry such as computer graphic design, short video shooting and editing, data statistics and analysis, and data processing, etc. Therefore, practical teaching is particularly important. Practical teaching activities are mainly composed of three parts: practice in the classroom, practice outside the classroom, and graduation practice. The practice in the classroom is integrated with professional and quality training, it's mainly conducted in the forms of course thesis instruction, laboratory scenario simulation, and practice guidance, etc. The practice outside the classroom includes the practical activities during winter and summer vacations and the quality development activities in the second classroom; first, the schools cooperate with enterprises to establish practical teaching bases outside the schools, and students could take internships in winter and summer vacations; second, students could participate in various practical activities held by social organizations, such as world-class intangible cultural heritage projects like Chinese paper-cutting, and the Three Gorges embroidery, etc.; the graduation practice is carried out during the senior year, students are assigned to enterprises and institutions for practical training and learning, so as to prepare them for the work positions they are about to take. 


\subsection{Construction of practical teaching mode in colleges and universities}

The professional talents of the cultural industry management major are not just innovative-type talents with rich professional and theoretical knowledge, they are also application-type talents that can work in private enterprises, public institutions, administrative departments and other organizations. Therefore, it's necessary to construct a novel practical teaching mode that can combine the requirements of job competence standards with the practical teaching schemes, and combine the intelligent practical teaching management cloud platform in schools with the intelligent function expansion of the off-campus school-enterprise cooperation platform.

1. Master the development situation of technologies in the cultural industry and create a new practical teaching mode supported by AI

First, establish an intelligent management cloud platform for practical teaching. Take the "SPOC + MOOC" as the main teaching method, combine online teaching with offline teaching, integrate inside-class learning and outside-class learning, and provide an online teaching environment that students could "learn at anytime, anywhere". Second, use AI to achieve services such as personalized learning and intelligent push. At last, master the job competence standards required by the cultural industry through the school-enterprise cooperation platform, and provide an accurate basis for formulating talent training programs of practical teaching, the new practical teaching mode is shown in Figure 1.
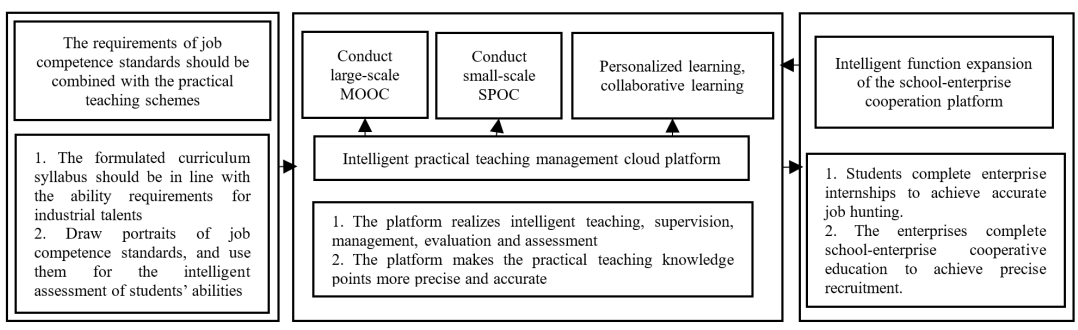

Fig. 1. The new practical teaching mode

2. Highly integrate job competence standards with cultivation of practical abilities, achieve accurate matching of technical points and knowledge points

The cultivation of the skills required by the job positions is separated into the practical teaching of the four college years, and the teaching, management, tracking, supervision, analysis, evaluation and assessment are conducted through the intelligent platform, as shown in Figure 2. As a result, the horizontal and precise matching of the practical teaching processes could be achieved. Students enter the enterprises and take trainings and internships during their senior year, then they could reach the skill level required by the enterprises upon graduation. 
Integration of job competence standards and practical ability cultivation

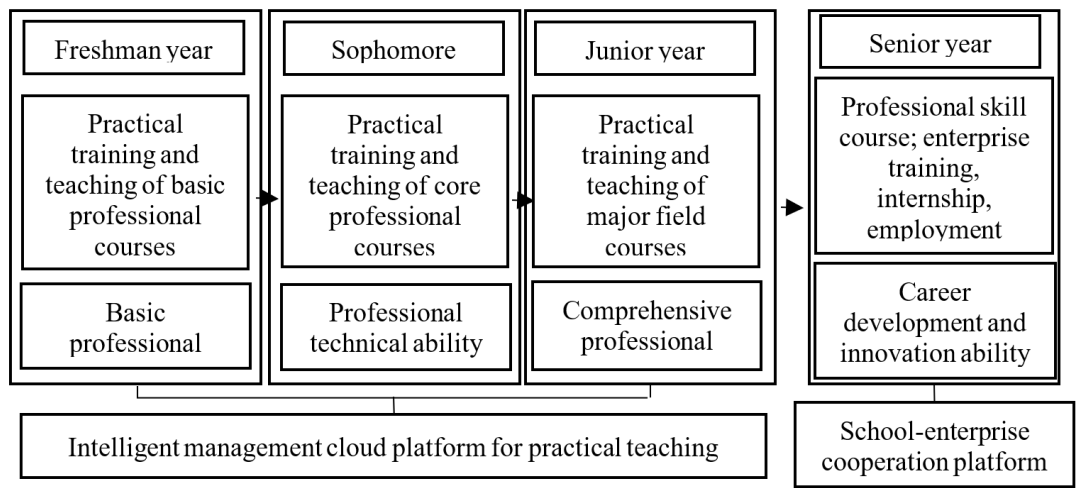

Fig. 2. Integration of job competence standards and practical ability cultivation

Subdivide the technical skills required by the job positions accurately in the vertical direction, as shown in Figure 3 (with "short video shooting and editing technique" as an example), and formulate corresponding knowledge points and content of the practical teaching.

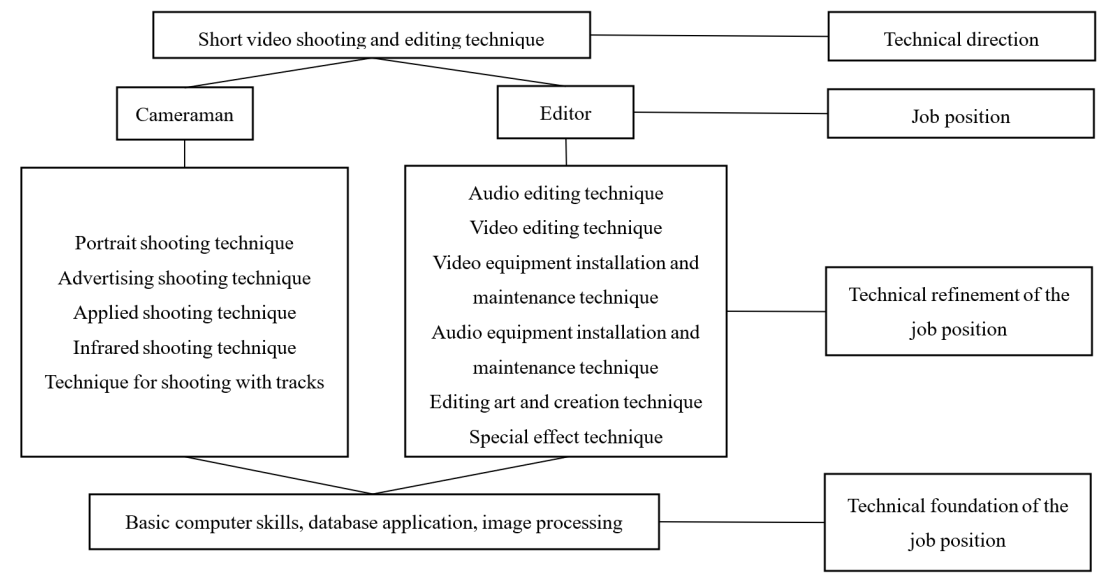

Fig. 3. An example of the subdivision of technical skills of a job position

\section{Construction of the Intelligent Management Cloud Platform for Practical Teaching}

The MOOC+SPOC platform seamlessly integrates the teaching content into the teaching scenarios, realizing instant sharing of high-quality teaching resources and big data. The offline practice teaching cloud platform intelligently manages the teaching process, realizing intelligent, accurate and standardized practical teaching. 


\subsection{Application of $\mathrm{AI}$ in practical teaching}

1. Intelligent evaluation for the operation of practice projects: the platform adopts a lightweight non-aligned convolutional neural network model to achieve intelligent evaluation of the practical operation process through deep learning, then based on the progress and accuracy of the students' operation, it gives the final scores of the practical courses according to the weight formula of teaching. At present, our school's evaluation of the practical teaching of the cultural industry management major is still focused on the finalized evaluation method, it lacks effective management of the teaching process, as well as the support of an informationalized and intelligent teaching platform; students hand in tasks at the end of the courses just to get it over with, and teachers are just in charge of assigning the tasks and giving final scores; the process of practical teaching doesn't have real-time process monitoring and evaluation, in the end, students don't really learn anything, and the teachers' teaching level stalls as well, which would affect the quality of practical teaching.

2. Automatic correction of practice reports and automatic testing of project codes: the platform uses applied statistics, semantic analysis, image recognition, optical character recognition, natural language processing and other technologies to conduct automatic recognition and error correction on simple terminologies and code specifications, and automatically generates practice reports and evaluation comments for the project codes. It can judge not only the surface features of the language, but also the quality of the content and the structure of the text, it can help teachers effectively correct the experimental reports, subjective questions, objective questions, short-answer questions, and questions of other forms, thereby improving the efficiency and scientificity of the teachers' review and comments, and meanwhile providing students with diagnosis reports of their personalized learning abilities. At present, the learning platforms used in our school, such as the Xuexitong, WeChat, and Rain Classroom, cannot yet intelligently evaluate the subjective questions.

3. Intelligent tracking, assessment and evaluation: the platform adopts big data and data analysis technologies to automatically track and record the students' learning process and the teachers' teaching process, and then give accurate analysis and evaluation on the learning and teaching situations. The intelligent evaluation system can perform keyword analysis, programming style analysis, error detection, and plagiarism detection on the program operations from four angles: structure, grammar, function, and overall complexity. For example, in the extracurricular practical course "Planning and Design of Cultural Creative Products", students are required to make cultural products in groups; however, since teachers do not participate in the process, they can't supervise the students all the time, and some students might enjoy "free ride" during the completion of the practice tasks. Therefore, using intelligent system to track, assess and evaluate students could avoid the occurrence of such situations.

4. Virtual learning assistant: with the help of technologies such as natural language processing, speech recognition, image recognition and data mining, the platform can virtually realize the role of extracurricular teachers, providing students with 
services such as online searching using photos of the questions, and accurate online Q\&A; students can quickly find out the corresponding analysis methods and detailed analysis processes from the massive question bank, meanwhile students' weak knowledge points could be quickly identified through the refined knowledge maps and labels, so that personalized guidance could be provided for them in a timely manner.

5. Learning path analysis: at first, the platform applies the preset job competence standard technical maps (such as cameraman and editor techniques) in stages and periods, then, after the application, it conducts big data mining according to the behavior data and behavior trajectories of students to obtain the accurate and objective technical knowledge maps; at last, it uses the optimized technical maps to match the optimal learning path for students.

6. Intelligent push: based on the learning data and records of college students, the platform constantly infers the problems and ability levels of college students, and pushes personalized practical learning content for them; the core is to push the most suitable learning materials and content for specific college students under the current learning path.

7. Adaptive learning: the platform makes use of the AI algorithms and suggests that every student should have one's own unique learning path; it automatically organizes the sequence of the knowledge points and gives optimal development models. The adaptive learning system creates learning models based on the big data of students' instant interactions, it conducts big data analysis on students' learning data, recommends learning resources and materials to students, and then adopts corresponding teaching methods and strategies, and finally achieving the ultimate purpose of enabling college students to realize personalized learning. Adaptive learning was developed from intelligent teaching systems and it's a new application of $\mathrm{AI}$ in the field of education; according to the constant changes of college students' learning trajectories, it could search for the optimal schemes at real time [10].

8. Personalized learning: first, it uses the Internet and big data to draw portraits for college students' actual abilities, create actual learning paths for their personalized learning, and push different learning content and plans for each student; then it scientifically collects the teaching data, accurately identifies the students' learning differences and weak knowledge points, pushes suitable learning methods and content from time to time according to the evaluation results of students' mastery of the teaching content, so as to meet students' requirements in personalized learning, predict their future learning situations, and improve the learning effect [11].

\subsection{Intelligent practical teaching management cloud platform}

The main functions of the platform include: intelligent management and supervision of practical teaching progress, intelligent scoring of practice projects, automatic duplicate checking, pre- and post-class self-tests of students, online Q\&A assistant, personalized push, learning situation reminder and warning, visualized display of practical teaching effect, intelligent analysis of teaching data, evaluation of teaching effect of teachers' courses, display of the portraits of students' personal skills, the 
portal for school-enterprise cooperation, and assistant to the precision employment, etc. [12-15].

\section{$5 \quad$ Form job Competence Standards and Students' Practical Ability Portraits Intelligently with the Help of AI}

AI makes big data collection and collation more efficient. With the help of the intelligent platform, we can track, assess and evaluate the development status of the actual technical abilities of college students throughout the whole process, and portraits of college students' practical abilities; moreover, using the school-enterprise cooperation platform, we can obtain portraits of the relevant job competence standards, thereby forming a contract of the abilities and standards, and ultimately achieving accurate job hunting for students and accurate recruitment for enterprises [16-18].

As shown in Figure 4, the job position of "short video editor" is taken as an example. For this job position, editors should have audio and video editing technique, audio and video equipment installation and maintenance technique, editing art creation technique, and special effects technique, etc. From this comparison chart, we can clearly know the actual abilities of college students, thereby accurately matching them with employment.

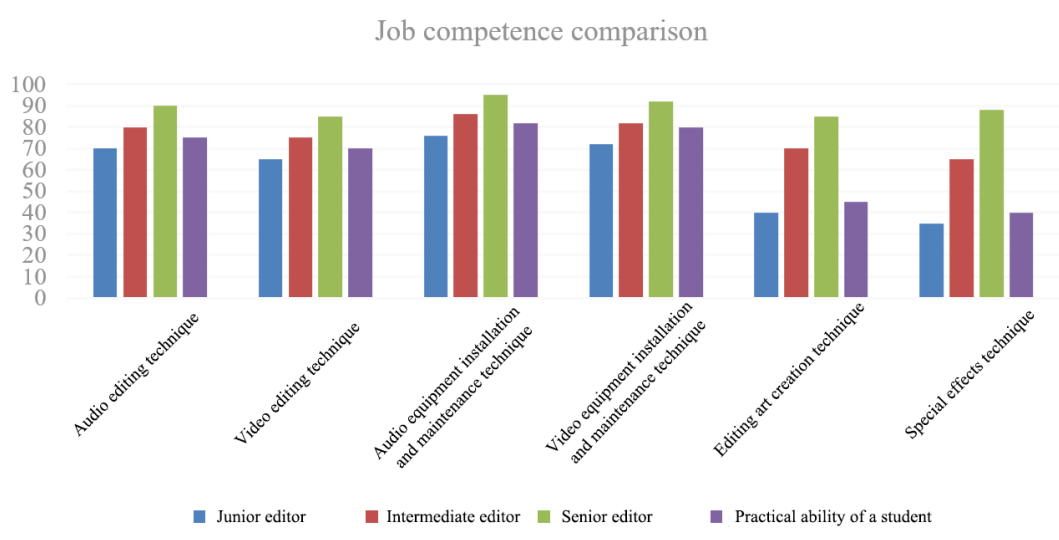

Fig. 4. Comparison of job competence standards and students' practical abilities

6 Optimization of the Intelligent Functions of the SchoolEnterprise Cooperation Platform, and Realization of the Accurate Matching of Talents' Practical Ability Cultivation between School and Enterprise

The proposed platform expands the functions of intelligent management and job recruitment of the school-enterprise cooperation platform; and the enterprises could 
directly monitor the situation of the actual abilities of each college student (showing in the form of ability portraits), so as to carry out practical training and internship activities more efficiently; at the same time, they can also participate in the drawing of the portraits of job competence standards, thereby reaching accurate matching of talents' practical ability cultivation between schools and enterprises as soon as possible [19]. According to the ability comparison results, enterprises can quickly and accurately find professional talents that could match the requirements of the job position, and college students can also accurately determine their professional development goals and directions, and quickly obtain the corresponding internship or job positions, thereby improving the employment quality of colleges and universities, and ultimately achieving a three-wins situation among schools, students, and enterprises [20-28].

\section{Conclusion}

With the help of AI technology, the high-quality practical teaching resources could be shared, achieving deep-level integration of online learning and offline learning, inside-class learning and outside-class learning, and personalized learning and collaborative learning; this paper accurately matched the job competence standards with the practical teaching plans, provided references for the talent cultivation schemes in colleges and universities, and optimized the teaching content and curriculum system from multiple angles and directions. Using the proposed intelligent teaching management cloud platform, we could perform intelligent management on each teaching link, give objective evaluation and accurate learning and teaching situation analysis, and provide data support for the reform of practical teaching; meanwhile, it enables teachers to have the time and energy to give personalized instruction and teaching to students, which has improved the work efficiency and effect of practical teaching. Through AI technology, intelligent push, and student learning path analysis, the proposed platform could achieve personalized learning, enhance students' independent learning ability, and improve their learning efficiency, thereby enabling college students to accurately determine their professional technical abilities and development directions and goals, and realizing precise employment. The intelligent schoolenterprise cooperation platform can provide comparison results of the job competence standards and the portraits of students' actual abilities, which enable the employer enterprises to rapidly understand college students' actual abilities and achieve accurate recruitment, and ultimately realizing a win-win situation between the school and the enterprise.

\section{Acknowledgement}

This work is supported by Chongqing Education Commission Humanities and Social Sciences under Grant No. 19SKSZ042; Chongqing Teaching Reform Project of Higher Education under Grant No. 193196. 


\section{References}

[1] Yao, Z. (2018) Action plan for artificial intelligence innovation in institutions of higher learning. Ministry of education, PRC. http://www.moe.gov.cn/srcsite/A16/s7062/201804/t20180410_332722.html

[2] Wang, B.H. (2012). An overview on the theory of artificial intelligence. Value Engineering, (4), 171-172.

[3] Sukhbaatar, O., Usagawa, T., Choimaa, L. (2019). An artificial neural network based early prediction of failure-prone students in blended learning course, International Journal of Emerging Technologies in Learning, 14(19), 77-92. https://doi.org/10.3991/ijet.v14i19.103 $\underline{66}$

[4] Nagata, K., Nakamura, T., Geurdes, H., Batle, J., Abdalla, S., Farouk, A. (2018). Creating very true quantum algorithms for quantum energy-based computing. International Journal of Theoretical Physics, 57(4), 973-980. https://doi.org/10.1007/s10773-017-3630-1

[5] Yang, X. (2019). An effective allocation model of computer teaching management resources based on particle swarm optimization, International Journal of Emerging Technologies in Learning, 14(18), 4-15. https://doi.org/10.3991/ijet.v14i18.11189

[6] Özbay, E., Çınar, A. (2019). A comparative study of object classification methods using 3D Zernike moment on 3D point clouds. Traitement du Signal, 36(6), 549-555. https://doi. org/10.18280/ts.360610

[7] Liu, J., LV, W.J. (2019). Artificial intelligence innovation and how to deal with China's higher education. Research in Higher Education of Engineering, (6), 18-23.

[8] Chen, J., Lv, W.J. (2017). A major shift of artificial intelligence and talents cultivation in emerging engineering education. Research in Higher Education of Engineering, (6), 18-23.

[9] Liu, J., Zhong, X.Q., Li, X.P. (2020). Artificial intelligence in education: progress, opportunities and challenges. Research in Higher Education of Engineering, (4), 120-130

[10] Wu, W. M., Chen, J.Y. (2018). Analysis of factors affecting college students' professional knowledge initiative and countermeasures. Jiangsu Business Theory, (3), 120-124

[11] Yuan, Y., Yu, M.M., Tao, Y.X., Gong, Z.W., Liu, J.M. (2018). Quantitative research on china's artificial intelligence industry policy based on text mining. Journal of China Academy of Electronics and Information Technology, 13(6), 663-668. http://dx.doi.org/10.3969/j.issn.1673-5692.2018.06.007

[12] Kedra, J., Gossec, L. (2020). Big data and artificial intelligence: Will they change our practice? Joint Bone Spine, (2), 107-109. https://doi.org/10.1016/j.jbspin.2019.09.001

[13] Zheng, C. (2017). An improved design and mode innovation of physical education teaching evaluation based on AI system. Revista de la Facultad de Ingenieria, 32(12), 610-616.

[14] Pan. Y. H. (2017). Special issue on artificial intelligence 2.0. Frontiers of Information Technology \& Electronic Engineering, 18, 1-2. http://dx.doi.org/10.1631/FITEE.1710000

[15] Shum, S.J.B., Luckin, R. (2019). Learning analytics and AI: Politics, pedagogy and practices. British Journal of Educational Technology, (12), 2785-2793. https://doi.org/10.1111/ bjet. 12880

[16] Meng, W.L., Mao, C.Z., Zhang, J., Wen, J., Wu, D.H. (2019). A fast recognition algorithm of online social network images based on deep learning. Traitement du Signal, 36(6), 575580. https://doi.org/10.18280/ts.360613

[17] Pantic, M., Zwitserloot, R., Grootjans, R.J. (2005). Teaching introductory artificial intelligence using a simple agent framework. IEEE Transactions on Education, 48(3), 382-390. https://doi.org/10.1109/te.2004.842906 
[18] Chouidira, I., Khodja, D.E., Chakroune, S. (2019). Induction machine faults detection and localization by neural networks methods. Revue d'Intelligence Artificielle, 33(6), 427-434. https://doi.org/10.18280/ria.330604

[19] Bogoviz, A.V., Lobova, S.V., Karp, M.V., Vologdin, E.V., Alekseev, A.N. (2019). Diversification of educational services in the conditions of industry 4.0 on the basis of AI training. On the Horizon, (2), 206-212. https://doi.org/10.1108/oth-06-2019-0031

[20] Yang, X. (2020). The connotation, approach and strategy of "Cognifying" education in artificial intelligence-How AI makes education smarter. China Educational Technology, (3), 25-31.

[21] Lin, L. (2020). An evaluation system and its model for educational competitiveness of universities. International Journal of Emerging Technologies in Learning, 15(11), 188-201. https://doi.org/10.3991/ijet.v15i11.14521

[22] Zhou, N. R., Liang, X. R., Zhou, Z. H., Farouk, A. (2016). Relay selection scheme for amplify and forward cooperative communication system with artificial noise. Security and Communication Networks, 9(11), 1398-1404. https://doi.org/10.1002/sec.1425

[23] Dede, C. J. (1988). Probable evolution of artificial-intelligence-based educational devices. Technological Forecasting and Social Change, 34(2), 115-133. https://doi.org/10.1016/004 0-1625(88)90061-3

[24] Zhong, S.C. (2020). How artificial intelligence supports educational revolution. China Educational Technology, (3), 17-24.

[25] Liu, J., Meng, X., Chen, C. (2020). Knowledge structure analysis on educational technology based on citation analysis. International Journal of Emerging Technologies in Learning (iJET), 15(5), 171-183. https://doi.org/10.3991/ijet.v15i05.13331

[26] Saddhono, K., Hasanudin, C., Fitrianingsih, A. (2019). The ability to think creatively on SSCS using schoology Apps, how is the student's language metacognitive awareness? Ingénierie des Systèmes d'Information, 24(4), 367-375. https://doi.org/10.18280/isi.240402

[27] Chen, L.J., Chen, P.P., Lin, Z.J. (2020). Artificial intelligence in education: A review. IEEE Access, (4), 75264-75278. https://doi.org/10.1109/ACCESS.2020.2988510

[28] Loftus, M., Madden, M.G. (2020). A pedagogy of data and artificial intelligence for student subjectification. Teaching in Higher Education, 25(4), 456-475. https://doi.org/10.10 $\underline{80 / 13562517.2020 .1748593}$

\section{Authors}

Cuibi Yang was born in Zhongxian, Chongqing, China in 1978. She received the Master's Degree in administrative management from University of Electronic Science and Technology of China (UESTC) in 2013. From 2003 to 2010, she was an English teacher in senior high school in Wanzhou, Chongqing, China. Since 2013, she has been a university lecturer with Institute of Public Management, Chongqing Three Gorges University. She is the author of two books, more than 20 articles. Her research interests include educational and teaching research, cultural industry management, cultural tourism. Ms Yang's awards and honors include a prominent teacher in Chongqing Three Gorges University in 2015 and Double-qualified Teachers in Chongqing Three Gorges University in 2016. Email: lisaycb1978@163.com

Shuliang Huan was born in Zhongxian, Chongqing, China in 1977. He received the Master's Degree in Chinese language and literature from Central China Normal University (CCNU) in 2005. Now he is studying for a Doctor's Degree at Southwest 
Jiaotong University. From 2002 to 2010, he was a lecturer with College of Arts, Chongqing Three Gorges University. Since 2011, he has been an Associate Professor with College of Arts, Chongqing Three Gorges University. He is an author of three books and more than 30 articles. His research interests include educational and teaching research, the study on folk culture and classical philology. Mr Huan was a recipient of prominent teachers and an excellent educator in Chongqing Three Gorges University in 2011 and 2018 separately, and a Director of Three Gorges Cultural Research Association, Director of Chongqing Three Kingdoms Cultural Research Association, a Double-qualified Teacher in Chongqing Three Gorges University in 2017. Email: 391988617@qq.com

Yong Yang was born in Zhongxian, Chongqing, China in 1987. He received the Master's Degree in Mechanical and Electrical Engineering from Guizhou University in 2014. Now he is studying for a Doctor's Degree at University of Science and Technology Beijing (USTB). Since 2014, he was a lecturer with School of Mechanical Engineering, Chongqing Three Gorges University. He is an author of one book and 10 articles, and more than 20 patents. His research interests include educational and teaching research, mechanical and electrical drive and hydraulic system control of engineering machinery. Mr Yang is a Double-qualified Teacher in Chongqing Three Gorges University in 2017 and an outstanding member of Communist Party in 2018. Email: 378576614@qq.com

Article submitted 2020-07-01. Resubmitted 2020-08-03. Final acceptance 2020-08-06. Final version published as submitted by the authors. 